\title{
Syntheses and Cytotoxicity of (R)- and (S)-7-Methoxycryptopleurine
}

Cintia Anton-Torrecillas, ${ }^{\mathrm{a}}$ Irene Bosque, ${ }^{\mathrm{a}}$ Jose C. Gonzalez-Gomez, ${ }^{\mathrm{a}, *}$ María Isabel Loza $^{\mathrm{b}}$ and José Brea ${ }^{\mathrm{b}}$

${ }^{a}$ Departamento de Química Orgánica, Facultad de Ciencias and Instituto de Síntesis

Orgánica (ISO), Universidad de Alicante, Apdo. 99, 03080 Alicante, Spain.

${ }^{\mathrm{b}}$ Grupo de Investigación Biofarma. USEF screening platform. Centro de Investigación en Medicina Molecular y Enfermedades Crónicas (CIMUS). Universidad de Santiago de Compostela. Avda de Barcelona s/n. Santiago de Compostela, Spain. josecarlos.gonzalez@ua.es

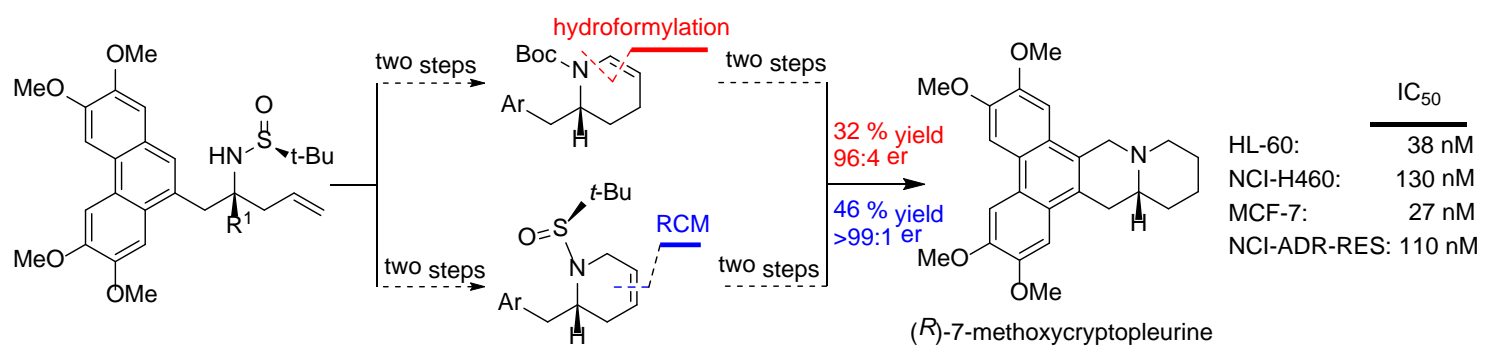

ABSTRACT: Two efficient protocols are described for the transformation of a key chiral homoallyllic sulfinamine intermediate in four steps into enantioenriched 7methoxycryptopleurine. While one of the protocols relied on a rhodium catalyzed linear hydroformylation process, the alternative approach was based on a ring-closing metathesis from the corresponding $\mathrm{N}$-allyl-sulfinamine. The cytotoxic evaluation of both enantiomers of the target compound demonstrated that the $(R)$-compound is much more potent than its antipode against the four cancer cell lines examined. 
Phenanthroizidine alkaloids exhibit a polyoxygenated phenanthrene ring fused to an indolizidine or to a quinolizidine system (Figure 1). ${ }^{1}$ Importantly, while the indolizidine moiety prefers a cis-fused conformation, ${ }^{2}$ trans-fused quinolizidines are preferred. ${ }^{3}$ The stereochemistry of the pyramidal nitrogen at the ring junction may accounts for some important differences between the bioactivities of these subfamilies of alkaloids. ${ }^{4}$

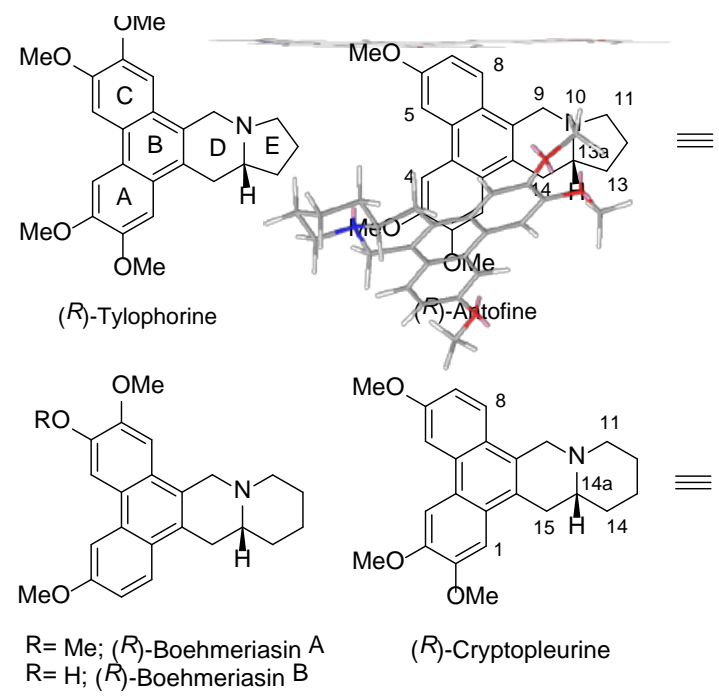

Figure 1. Representative natural phenanthroizidine alkaloids.

Cryptopleurine $^{5}$ and Cryptopleuridine $^{6}$ were the only two natural phenathroquinolizidines known until 2002. Despite their lower natural occurrence compared to the indolizidine subfamily, phenanthroquinolizidines also exhibit very interesting bioactivities. This issue can be exemplified by Boehmeriasin A, which was identified in $2003^{7}$ and exhibited $\mathrm{IC}_{50}$ in the low nanomolar range against twelve cancer cell lines. ${ }^{8}$ Other structure-activity relationships (SAR) studies have also revealed that phenanthroquinolizidines are more potent anti-tumor agents than phenanthroindolizidine alkaloids. ${ }^{9}$ Encouraged by the discovery of natural phenanthroquinolizidines with important biological properties, some elegant asymmetric syntheses have been recently reported for these compounds. ${ }^{10,11}$ 
It is reported that racemic 7-methoxycryptopleurine ${ }^{12}$ displays potent anti-inflamatory activity, ${ }^{13}$ as well as remarkable cytotoxicity at submicromolar concentrations against different human cancer cell lines. ${ }^{3 a, 14}$ In addition, the group of Wang has found that both enantiomers of the title compound show significant antiviral activity (in vitro and in vivo) against tobacco mosaic virus (TMV), being the $R$-enantiomer the most active one. ${ }^{15}$ Moreover, the same group has recently reported that different salts of the title compound, or derivatives where the methyl groups were removed, gave excellent anti TMV activity. ${ }^{16}$ To our best knowledge, the only enantioselective synthesis reported for this promising bioactive compound takes place with partial racemization over a Parham-type cycloacylation. ${ }^{17}$

Prompted by the unique biological activities of 7-methoxycryptopleurine and the lack of efficient protocols for its preparation with high enantiomeric purity, we report herein two alternative protocols for the synthesis of enantioenriched $(R)$ - and $(S)$-7methoxycryptopleurine. Both synthetic strategies relied on a late Pictet-Spengler formation of ring $\mathrm{D}^{18}$ and the formation of ring $\mathrm{E}$ was examined using either hydroformylation or ring-closing metathesis $(\mathrm{RCM})^{19}$ as the key steps, from the same chiral homoallylic sulfinamine intermediate ${ }^{20}$ (Scheme 1). Since we have previously shown that these chiral intermediates can be efficiently transformed into phenanthroindolizidines, ${ }^{21}$ this work illustrates the versatility of these building blocks in the synthesis of both subfamilies of phenanthroizidine alkaloids. ${ }^{22}$

Scheme 1. Divergent synthesis of two subfamilies of phenanthroizidine alkaloids.

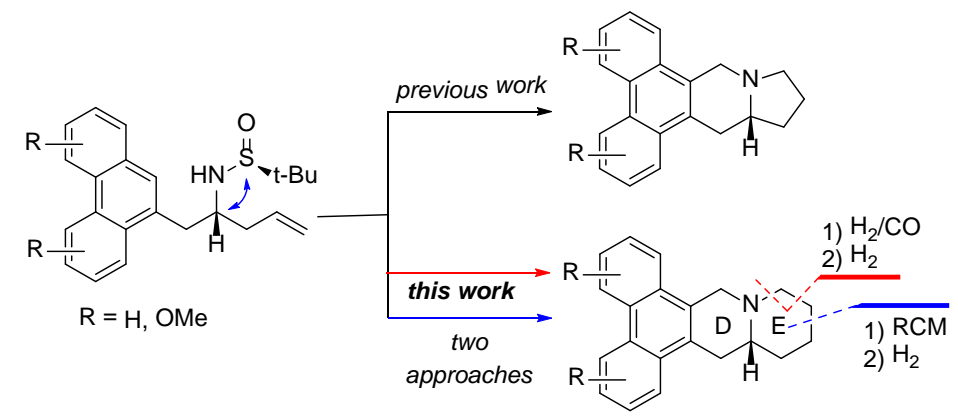


Our first strategy to build ring $\mathrm{E}$ of $(R)$-7-methoxycryptopleurine is based on a linear hydroformylation of the corresponding homoallylic amine intermediate. This approach has been widely used for a range of aminoalkenes in order to provide terminal aldehydes, which upon cyclization give enamine intermediates that can be transformed into different aza-heterocycles. ${ }^{23}$ In this regard, we were particularly attracted by a rhodium catalyzed procedure where the syngas $\left(\mathrm{CO} / \mathrm{H}_{2}\right)$ is conveniently substituted by formaldehyde, with excellent linear selectivity. ${ }^{24}$ To minimize functional group manipulations and reduce the number of steps, we first tried the direct hydroformylation of sulfinamine 1, which can be prepared in six steps from commercially available starting materials ${ }^{21}$ (Scheme 2). However, compound 1 proved to be unreactive under different conditions reported in the literature for the rhodium(I) catalyzed hydroformylation with formalin (37\% aq. formaldehyde) or paraformaldehyde. We thus prepared the $N$-Boc protected homoallylic amine 2, which was submitted to rhodium(I) catalyzed hydroformylation with formalin, using two different phosphane ligands (BIBHEP and Ni-Xantphos). Under these conditions, the formation of the corresponding terminal aldehyde was followed by in-situ cyclization to furnish the protected enamine 3 in moderate yield (Scheme 2). Subsequent hydrogenation of the enamine moiety followed by acidic cleavage of the Boc group took place efficiently to obtain piperidine 4. Finally, the Pictet-Spengler cyclomethylenation of this precursor was accomplished under standard conditions (formalin, $\mathrm{HCl}, \mathrm{EtOH}, 90^{\circ} \mathrm{C}$ ) to obtain the target (R)-7-methoxycryptopleurine in good yield. The spectroscopic data obtained for compound 5 perfectly match with data previously reported for racemic 7methoxycryptopleurine ${ }^{3 a}$ and the chiral HPLC analysis of this compound shows that racemization did not take place over the synthetic sequence (96:4 er, see SI). It is worth 
noting that the absolute configuration of compound 5 was confirmed to be $14 a-R$ by comparison of the specific rotation value obtained for our synthetic sample $\left\{[\alpha]_{\mathrm{D}}{ }^{20}-81\right.$ (c 1.0, $\left.\left.\mathrm{CHCl}_{3}\right)\right\}$ with the one reported in the literature ${ }^{17}\left\{[\alpha]_{\mathrm{D}}{ }^{20}-74.8\left(\mathrm{c} 0.5, \mathrm{CHCl}_{3}\right)\right\}$.

Scheme 2: Synthesis of (R)-7-Methoxycryptopleurine using Hydroformylation

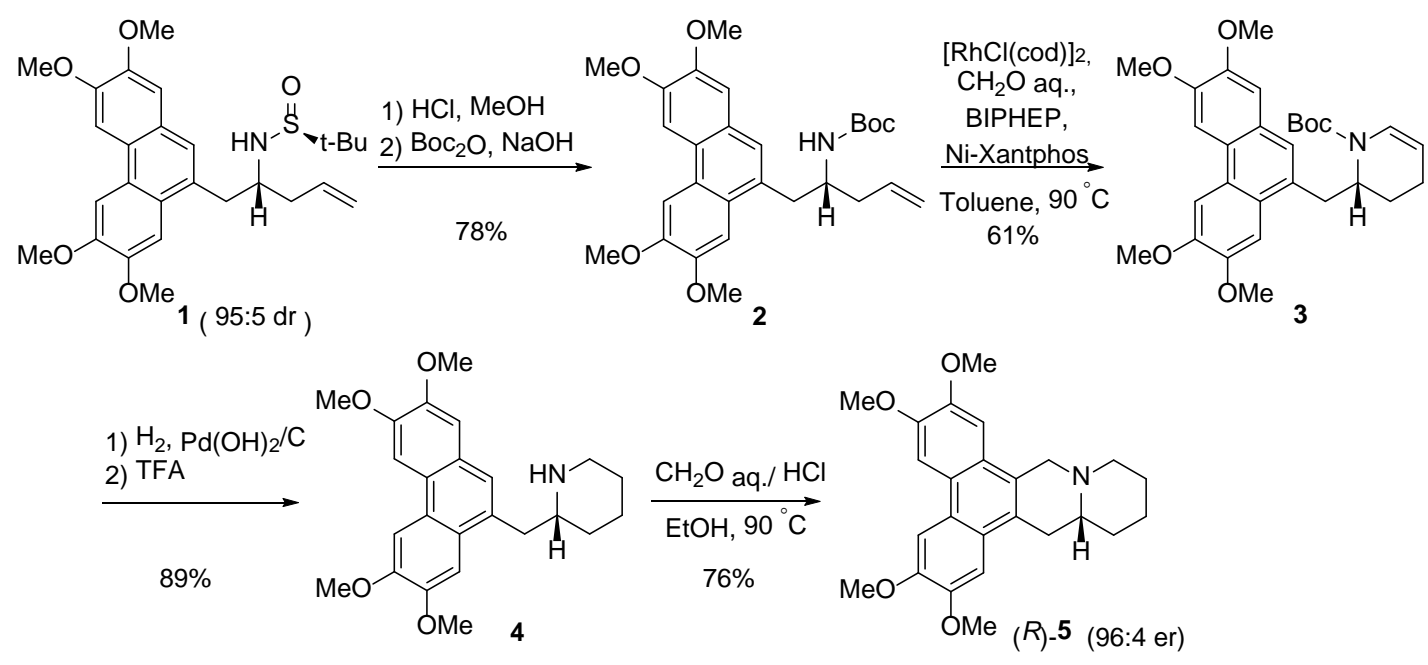

Despite the good results obtained in the synthesis of compound $(R)-5$ [32\% yield over four purification steps from compound 1 to obtain $(R)-\mathbf{5}$ in 96:4 er], we were particularly interested in keeping the sulfinyl as protecting group throughout the synthetic sequence. With this strategy we anticipated a concomitant nitrogen deprotection and Pictet Spengler annulation in the final step. More importantly, we expected that keeping the chiral auxiliary until the last step would offer more opportunities to improve the enantiomeric purity of compound $\mathbf{5}$ by separation of diastereomeric intermediates. To carry forward this approach (Scheme 3) we first performed the $N$-allylation of compound $\mathbf{6},{ }^{25}$ followed by ring-closing metathesis (RCM). At the outset it was not clear if the sulfinyl group would compete with the alkene moiety by the ruthenium carbene complex, preventing the desired cyclization. ${ }^{26}$ Remarkably, after only one hour at room temperature, the use of commercially available second-generation Grubbs catalyst allowed the RCM reaction to proceed with almost 
quantitative yield. Catalytic hydrogenation of intermediate 8a was accomplished by using Adams`s catalyst to give compound $9 \mathbf{a}^{27}$ followed by acidic removal of the sulfinyl group and Pictet Spengler annulation. Phenanthroquinolizidine (S)-10 was obtained in 68\% yield over four purification steps from compound 6. The same synthetic sequence was applied to obtain $(R)-\mathbf{1 0}$ from ent-6 with similar efficiency in terms of isolated yields, and neither racemization nor significant enantioenrichment was observed by chiral HPLC analysis of the products (see SI). Having developed this protocol, we thus carried out the synthesis of target compound (S)-5 from compound ent-1. $^{21}$ Importantly, this synthetic protocol allowed the preparation of (S)-7methoxycryptopleurine as a single isomer (>99:1 er by HPLC analysis), in 46\% yield over four purification steps. The enantioenrichment of the target compound was simply achieved after conventional flash chromatography purifications of diastereomeric $\mathbf{8 b}$ and $\mathbf{9 b}$ intermediates, according to chiral HPLC analysis (see SI).

Scheme 3. Synthesis of Phenanthroquinolizidines using RCM

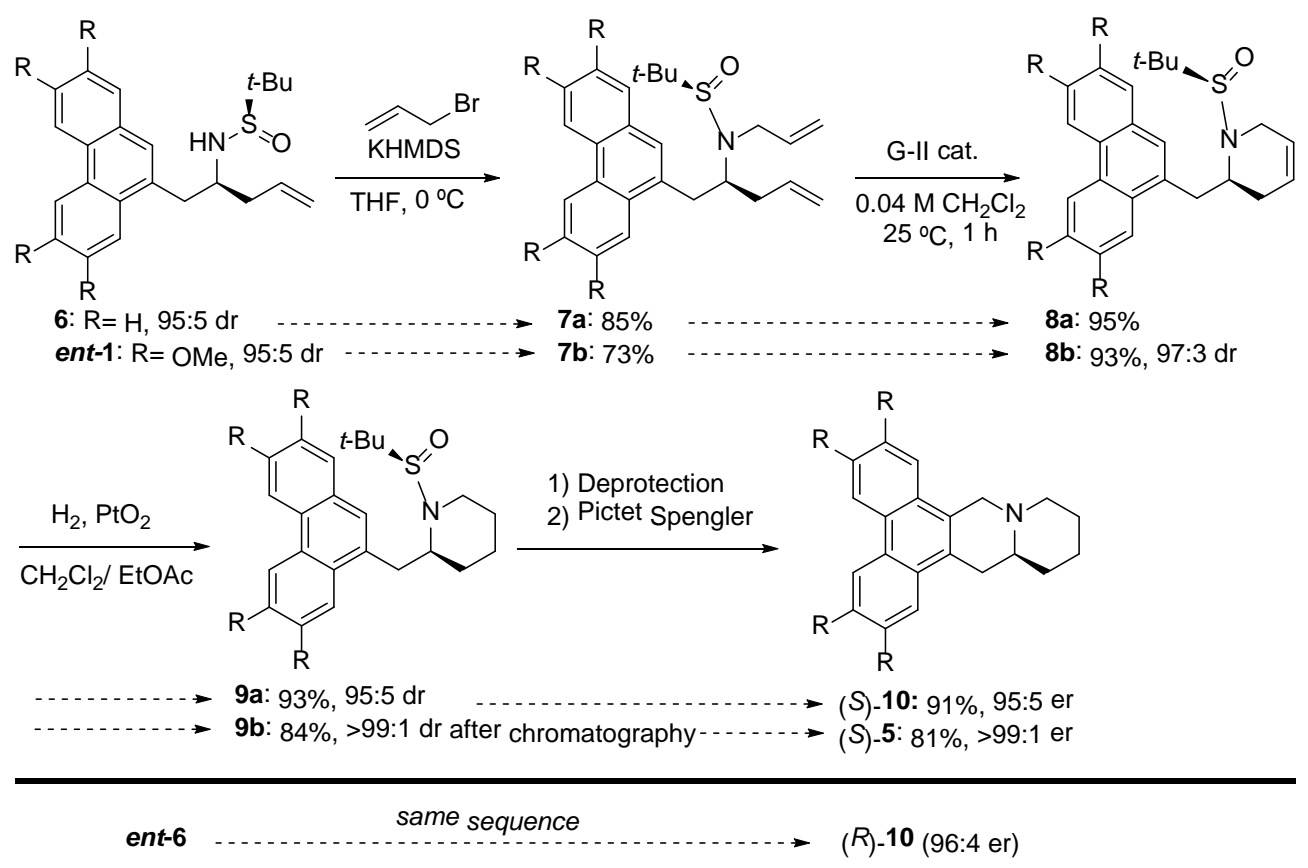


The cytotoxic activities of synthesized $(R)$-and $(S)$-7-methoxycryptopleurine were tested against four human cancer cell lines, using the MTT (3-[4,5-dimethylthiazol-2-yl]-2,5diphenyltretrazolium bromide) method and CDDP [cis-diaminedichloroplatinum (II)] as positive control. The $\mathrm{IC}_{50}$ values were determined from the corresponding inhibition/concentration curves (see SI) and the results are shown in Table 1. In all the cell lines evaluated the compound with the $(R)$-configuration (as natural analogues) was much more potent ( $\mathrm{IC}_{50}$ from 0.027 to $0.13 \mu \mathrm{M}$ ) than its $(S)$-enantiomer ( $\mathrm{IC}_{50}$ from 0.97 to $76 \mu \mathrm{M}$ ), confirming the importance of this configuration in their cytotoxicity. The cytotoxicity obtained for compound (R)-5 against human lung cancer cell lines (NCIH460) was similar to the one previously reported ${ }^{3 a}$ for a racemic sample. However, for human breast cancer cell lines (MCF-7), compound (R)-5 showed a significant higher potency than it is reported for a racemic sample. A profound cytotoxicity was also exhibited by compound (R)-5 against human leukemia cells (HL-60); and most significantly against drug resistant human ovarian adenocarcinoma (NCI-ADR-RES), where paclitaxel -a potent anticancer agent ${ }^{11}$ is inactive.

Table 1. Cytotoxicity Evaluation of (R)-and (S)-7-Methoxycryptopleurine

Compounds

$$
\mathrm{IC}_{50}(\mu \mathrm{M})^{\mathbf{a}}
$$

$$
H L-60^{\mathrm{b}} \quad N C I-H 460^{\mathrm{c}} \quad M C F-7^{\mathrm{d}} \quad N C I-A D R-R E S^{\mathrm{e}}
$$

CDDP

$( \pm)-5$

(R)-5 $\mathrm{HCl}$

$0.038 \pm 0.001$

$0.13 \pm 0.06$

$0.027 \pm 0.001$

$1.2 \pm 0.1$

$0.97 \pm 0.04 \quad 76^{\mathrm{g}} \pm 11$$$
1.2 \pm 0.1
$$

${ }^{\mathrm{a}}$ Average of three assays each. ${ }^{\mathrm{b}} \mathrm{HL}-60=$ human promyelocytic leukemia. ${ }^{\mathrm{c}} \mathrm{NCI}-\mathrm{H} 460=$ human lung carcinoma. ${ }^{\mathrm{d}} \mathrm{MCF}-7$ = human breast carcinoma. ${ }^{\mathrm{e}} \mathrm{NCI}-\mathrm{ADR}-\mathrm{RES}=$ drug-resistant human ovarian adenocarcinoma. ${ }^{\mathrm{f}}$ Taken from reference 3a. ${ }^{\mathrm{g}}$ Extrapolated values from an incomplete 
In conclusion, we have developed two alternative procedures that allow the enantioselective preparation of 7-methoxycryptopleurine (5) in four purification steps from the same chiral homoallyllic sulfinamine. The synthetic approach that make use of linear hydroformylation for the construction of ring $\mathrm{E}$ afforded the target compound in good overall yield (32\%) and enantiomeric purity (96:4 er). However, better results were obtained using the ring-closing metathesis of the $N$-allyl-sulfinamine intermediate (46\% overall yield in >99:1 er). The cytotoxicity of each enantiomer of compound 5 was evaluated against four cancer cell lines, including a drug-resistant cancer cell line, obtaining more prominent activities for the $(R)$-antipode ( $\mathrm{IC}_{50}$ up to $27 \mathrm{nM}$ ). To the best of our knowledge, the two procedures developed herein allow the preparation of the target compound with the highest enantiomeric purity reported to date. The cytotoxicities obtained for compound $(R)-\mathbf{5}$ clearly support this candidate as a promising anticancer agent.

\section{EXPERIMENTAL SECTION}

General Remarks. TLC was performed on silica gel $60 \mathrm{~F}_{254}$, using aluminum plates and visualized by exposure to ultraviolet light or with phosphomolybdic acid (PMA) stain. Flash chromatography was carried out on handpacked columns of silica gel 60 (230 - 400 mesh). Melting points are uncorrected. Optical rotations were measured using a polarimeter with a thermally jacketted $5 \mathrm{~cm}$ cell at approximately $20{ }^{\circ} \mathrm{C}$ and concentrations (c) are given in g/100 mL. Infrared analysis was performed with a spectrophotometer equipped with an ATR component; wavenumbers are given in $\mathrm{cm}^{-1}$. HRMS analyses were carried out using the Electron Impact (EI) mode at $70 \mathrm{eV}$ or by Q- 
TOF using Electro Spray Ionization (ESI) mode. HPLC analyses were performed using an achiral Tracer Excel 120 column for the determination of diastereomeric ratios and a Chiralcel AD-H column for enantiomeric ratios. ${ }^{1} \mathrm{H}$ NMR spectra were recorded at 300 or $400 \mathrm{MHz}$ for ${ }^{1} \mathrm{H}$ NMR and 75 or $100 \mathrm{MHz}$ for ${ }^{13} \mathrm{C}$ NMR, using $\mathrm{CDCl}_{3}$ as the solvent and TMS as an internal Standard (0.00 ppm). The data is being reported as ( $\mathrm{s}=$ singlet, $\mathrm{d}=$ doublet, $\mathrm{t}=$ triplet, $\mathrm{m}=$ multiplet or unresolved, br $\mathrm{s}=$ broad signal, coupling constant(s) in $\mathrm{Hz}$, integration). ${ }^{13} \mathrm{C}$ NMR spectra were recorded with ${ }^{1} \mathrm{H}$-decoupling at $100 \mathrm{MHz}$ and referenced to $\mathrm{CDCl}_{3}$ at $77.16 \mathrm{ppm}$. DEPT-135 experiments were performed to assign $\mathrm{CH}, \mathrm{CH}_{2}$ and $\mathrm{CH}_{3}$.

\section{(R)-tert-Butyl-1-(2,3,6,7-tetramethoxyphenanthren-9-yl)pent-4-en-2-ylcarbamate}

(2). To a solution of compound $\mathbf{1}^{21}$ (596 mg, $1.23 \mathrm{mmol}$, 95:5 dr) in $\mathrm{MeOH}(15 \mathrm{~mL}$ ) was added a solution of $4 \mathrm{M} \mathrm{HCl}$ in dioxane $(1.2 \mathrm{~mL}, 5.00 \mathrm{mmol})$ at $0{ }^{\circ} \mathrm{C}$. The cooling bath was removed and the reaction mixture was stirred $1.5 \mathrm{~h}$ at $25{ }^{\circ} \mathrm{C}$, before being concentrated to dryness. The resulting free amine was dissolved in $\mathrm{CH}_{2} \mathrm{Cl}_{2}(12 \mathrm{~mL})$ and after cooled down the solution to $0{ }^{\circ} \mathrm{C}$, a solution of $2 \mathrm{M} \mathrm{NaOH}(12 \mathrm{~mL})$ and $\mathrm{Boc}_{2} \mathrm{O}$ (304 mg, $1.40 \mathrm{mmol}$ ) were sequentially added. The mixture was stirred under argon atmosphere at $25^{\circ} \mathrm{C}$ during $2.5 \mathrm{~h}$. The mixture was extracted with $\mathrm{CH}_{2} \mathrm{Cl}_{2}(5 \times 10 \mathrm{~mL})$ and the collected organic layers were washed with brine ( $5 \mathrm{~mL})$, dried over $\mathrm{MgSO}_{4}$ and concentrated to dryness. The crude product was purified by flash chromatography (hexane/EtOAc from 7:3 to 1:1) to obtain the desired product as a white amorphous solid (458 mg, 78\%): $[\alpha]_{\mathrm{D}}{ }^{20}-10$ (c $\left.0.4, \mathrm{CHCl}_{3}\right) ; \mathrm{R}_{\mathrm{f}} 0.26$ (7:3 hexane/EtOAc); IR $v$ 3363, 3355, 3002, 2928, 2830, 1687, 1253, 1148, 1038, $835 \mathrm{~cm}^{-1}$; ${ }^{1} \mathrm{H}$ NMR (400 MHz, $\left.\mathrm{CDCl}_{3}\right) \delta 7.93(\mathrm{~s}, 1 \mathrm{H}), 7.83(\mathrm{~s}, 1 \mathrm{H}), 7.78(\mathrm{~s}, 1 \mathrm{H}), 7.39$ (s, 1H), 7.16 (s, 1H), $5.91-5.76$ (m, 1H), 5.15 - 5.11 (m, 2H), 4.62 (br s, 1H), 4.16 (s, 3H), 4.13 (s, 3H), 4.12 (s, 3H), 
4.03 (s, 3H), $3.80-3.73$ (m, 1H), $3.68-3.54$ (m, 1H), $2.96-2.84$ (m, 1H), $2.41-2.29$ (m, 1H), $2.25-2.11(\mathrm{~m}, 1 \mathrm{H}), 1.44(\mathrm{~s}, 9 \mathrm{H}) \mathrm{ppm} ;{ }^{13} \mathrm{C}$ NMR (101 MHz, $\left.\mathrm{CDCl}_{3}\right) \delta 155.6$ (C), $149.08(C), 149.05(C), 148.9(C), 134.6(C H), 130.6(C), 126.2(C), 125.9(C)$, $125.7(\mathrm{CH}), 124.9(\mathrm{C}), 124.0(\mathrm{C}), 118.4\left(\mathrm{CH}_{2}\right), 108.0(\mathrm{CH}), 105.9(\mathrm{CH}), 103.3(\mathrm{CH})$, $102.9(\mathrm{CH}), 56.5\left(\mathrm{CH}_{3}\right), 56.2\left(\mathrm{CH}_{3}\right), 56.1\left(\mathrm{CH}_{3}\right), 56.0\left(\mathrm{CH}_{3}\right), 50.2(\mathrm{CH}), 39.8\left(\mathrm{CH}_{2}\right)$, $37.7\left(\mathrm{CH}_{2}\right), 28.5(\mathrm{C}) \mathrm{ppm}$; HRMS (ESI-TOF) $\mathrm{m} / \mathrm{z}$ calcd for $\mathrm{C}_{28} \mathrm{H}_{35} \mathrm{NO}_{6} \mathrm{Na}$ 504.2362, found 504.2366.

\section{(R)-tert-Butyl-2-((2,3,6,7-tetramethoxyphenanthren-9-yl)methyl)-3,4-}

dihydropyridine-1-(2H)-carboxylate (3). To a pressure tube were sequentially added $[\mathrm{RhCl}(\mathrm{cod})]_{2}$ (3.10 mg, $\left.0.0062 \mathrm{mmol}\right)$, BIPHEP (6.63 mg, $0.0126 \mathrm{mmol}$ ), Ni-Xantphos (2.9 mg, $0.0126 \mathrm{mmol}$ ) and toluene (3.7 mL). The system was then evacuated and filled with argon before compound 2 (300 mg, $0.621 \mathrm{mmol}$ ) and aqueous formalin (37\%, 0.2 $\mathrm{mL}, 8.40 \mathrm{mmol}$ ) were added. The reaction mixture was deoxygenated via three cycles of freeze-pump and thaw under argon atmosphere and heated to $90{ }^{\circ} \mathrm{C}$. The mixture was stirred for $40 \mathrm{~h}$ at the same temperature and then left to reach room temperature, before being concentrated and purified by flash chromatography (hexane/EtOAc 7:3) to obtain the desired product as a white amorphous solid $(188 \mathrm{mg}, 61 \%)$ : $[\alpha]_{\mathrm{D}}{ }^{20}-51$ (c 1.0, $\left.\mathrm{CHCl}_{3}\right) ; \mathrm{R}_{\mathrm{f}} 0.33$ (7:3 hexane/EtOAc); IR v 2998, 2965, 2928, 2837, 1689, 1651, 1251, $752 \mathrm{~cm}^{-1} ;{ }^{1} \mathrm{H}$ NMR (400 MHz, $\mathrm{CDCl}_{3}$ ) $\delta 8.19$ (s, 1H), 7.83 (s, 1H), 7.79 (s, 1H), 7.38 (s, 1H), 7.17 (s, 1H), 6.83 (d, $J=8.4 \mathrm{~Hz}, 1 \mathrm{H}), 4.94-4.85$ (m, 1H), $4.79-4.66$ (m, 1H), 4.23 (s, 3H), 4.13 (s, 3H), 4.12 (s, 3H), 4.03 (s, 3H), 3.45 (dd, $J=13.7,2.9 \mathrm{~Hz}, 1 \mathrm{H}$ ), $3.09-2.95$ (m, 1H), $2.52-2.38$ (m, 1H), $2.08-1.96$ (m, 1H), $1.79-1.69$ (m, 1H), 1.51 (s, 9H) ppm; ${ }^{13} \mathrm{C}$ NMR (101 MHz, $\left.\mathrm{CDCl}_{3}\right) \delta 152.2(C), 149.2(C), 149.05(C), 149.01$ (C), $148.8(C), 130.8(C), 126.2(C), 126.1(C), 125.7(C H), 124.9(C), 124.7(C H)$, 124.1(C), $108.0(\mathrm{CH}), 106.3(\mathrm{CH}), 104.0(\mathrm{CH}), 103.1(\mathrm{CH}), 103.0(\mathrm{CH}), 80.7(C), 56.7$ 
(CH $\left.\mathrm{CH}_{3}\right), 56.2\left(\mathrm{CH}_{3}\right), 56.1\left(\mathrm{CH}_{3}\right), 56.01\left(\mathrm{CH}_{3}\right), 49.6(\mathrm{CH}), 35.1\left(\mathrm{CH}_{2}\right), 28.5\left(\mathrm{CH}_{3}\right), 21.9$

$\left(\mathrm{CH}_{2}\right), 17.6\left(\mathrm{CH}_{2}\right)$ ppm; HRMS (ESI-TOF) $\mathrm{m} / \mathrm{z}$ calcd for $\mathrm{C}_{29} \mathrm{H}_{35} \mathrm{NO}_{6} \mathrm{Na}$ 516.2362, found 516.2343.

(R)-2-((2,3,6,7-Tetramethoxyphenanthren-9-yl)methyl)piperidine (4). A dry flask was charged with compound 3 (168 mg, $0.34 \mathrm{mmol}), \mathrm{Pd}(\mathrm{OH})_{2}(20 \% \mathrm{Pd}$ on carbon powder with ca $60 \%$ moisture, $98 \mathrm{mg}, 0.09 \mathrm{mmol})$ and methanol $(10 \mathrm{~mL})$. A ballon of hydrogen gas was fitted to the equipment, and the flask was opened to vacuum for a few seconds, and then switched to the hydrogen ballon; this manipulation was repeated three times. The reaction mixture was allowed to stir at room temperature for $6 \mathrm{~h}$. It was then filtered throught Celite, washing with EtOAc ( $3 \times 15 \mathrm{~mL})$, and the organic solution was concentrated to dryness under reduced pressure. To the obtained residue were added methanol (3.0 mL), trifluoroacetic acid $(3.0 \mathrm{~mL}, 28.00 \mathrm{mmol})$ and $\mathrm{CH}_{2} \mathrm{Cl}_{2}(3 \mathrm{~mL})$ and the reaction mixture was stirred under argon at room temperature for $24 \mathrm{~h}$. After the mixture was concentrated to dryness, a solution $2 \mathrm{M}$ of $\mathrm{NaOH}(5 \mathrm{~mL}, 10 \mathrm{mmol})$ and $\mathrm{CH}_{2} \mathrm{Cl}_{2}(10 \mathrm{~mL})$ were added to the same flask. The aqueous phase was extracted with $\mathrm{CH}_{2} \mathrm{Cl}_{2}$ (3 x $\left.10 \mathrm{~mL}\right)$ and washed with brine $(5 \mathrm{~mL})$, dried over $\mathrm{Na}_{2} \mathrm{SO}_{4}$, and concentrated. The crude product was obtained as a brown amorphous solid (109 mg, 89 \%): $[\alpha]_{\mathrm{D}}{ }^{20}-4.8\left(\right.$ c $\left.0.5, \mathrm{CHCl}_{3}\right) ; \mathrm{R}_{\mathrm{f}} 0.27$ (95:5, $\left.\mathrm{CH}_{2} \mathrm{Cl}_{2} / \mathrm{MeOH}\right) ;{ }^{1} \mathrm{H}$ NMR (300 MHz, $\left.\mathrm{CDCl}_{3}\right) \delta 7.83(\mathrm{~s}, 1 \mathrm{H}), 7.76(\mathrm{~s}, 1 \mathrm{H}), 7.46(\mathrm{~s}, 1 \mathrm{H}), 7.42(\mathrm{~s}, 1 \mathrm{H}), 7.16(\mathrm{~s}, 1 \mathrm{H}), 4.12$ (s, 3H), 4.11 (s, 3H), 4.06 (s, 3H), 4.02 (s, 3H), 3.24 (dd, $J=13.4,4.6 \mathrm{~Hz}, 1 \mathrm{H}), 3.11-2.87$ (m, 3H), 2.51 (td, $J=11.5,3.0 \mathrm{~Hz}, 1 \mathrm{H}), 1.88-1.72$ (m, 2H), 1.55 - 1.26 (m, 4H) ppm; ${ }^{13} \mathrm{C}$ NMR (75 MHz, $\left.\mathrm{CDCl}_{3}\right) \delta 149.1(C), 149.0$ (2xC), $148.7(C), 130.5(C), 126.3(C)$, $125.6(\mathrm{CH}), 125.5(\mathrm{C}), 125.2(\mathrm{C}), 123.9(\mathrm{C}), 108.1(\mathrm{CH}), 105.2(\mathrm{CH}), 103.5(\mathrm{CH})$, $102.9(\mathrm{CH}), 56.7\left(\mathrm{CH}_{3}\right), 56.3\left(\mathrm{CH}_{3}\right), 56.2\left(\mathrm{CH}_{3}\right), 56.0\left(\mathrm{CH}_{3}\right), 47.2(\mathrm{CH}), 41.6\left(\mathrm{CH}_{2}\right)$, 
33.4 $\left(\mathrm{CH}_{2}\right)$, $26.1\left(\mathrm{CH}_{2}\right), 25.0\left(\mathrm{CH}_{2}\right)$ ppm; HRMS (ESI-TOF) $\mathrm{m} / \mathrm{z}$ calcd for $\mathrm{C}_{24} \mathrm{H}_{30} \mathrm{NO}_{4}$ 396.2175, found 396.2172.

(R)-7-Methoxycryptopleurine ((R)-5). To a solution of compound 4 (100 mg, 0.25 mmol) in EtOH $(6 \mathrm{~mL})$ was added $37 \%$ aqueous formaldehyde $(1.25 \mathrm{~mL})$ and concentrated $\mathrm{HCl}(12 \mathrm{M}, 0.18 \mathrm{~mL})$. The mixture was put under argon atmosphere in the dark and heated to $90{ }^{\circ} \mathrm{C}$ with stirring for $48 \mathrm{~h}$. After cooled to room temperature, the mixture was concentrated and distributed between $2 \mathrm{M}$ solution of $\mathrm{NaOH}(10 \mathrm{~mL})$ and $\mathrm{CH}_{2} \mathrm{Cl}_{2}(15 \mathrm{~mL})$. The aqueous phase was extracted with $\mathrm{CH}_{2} \mathrm{Cl}_{2}(3 \times 15 \mathrm{~mL})$ and the collected organic layers were washed with brine $(5 \mathrm{~mL})$, dried over $\mathrm{Na}_{2} \mathrm{SO}_{4}$, and concentrated in vacuum. The crude product was purified by flash chromatography (72:25:2:1, hexane/ $\mathrm{CH}_{2} \mathrm{Cl}_{2} / \mathrm{EtOH} / \mathrm{TEA}$ ), to obtain the desired product as a yellow solid (185 mg, 76\%): mp 236-240 ${ }^{\circ} \mathrm{C}$ (descomp.); $\left\{\right.$ lit. $^{3 \mathrm{a}} \mathrm{mp} 245-247{ }^{\circ} \mathrm{C}$ (descomp.) $\} ;[\alpha]_{\mathrm{D}}{ }^{20}$ -81 (c 1.0, $\left.\mathrm{CHCl}_{3}\right) \quad\left\{\right.$ lit. $^{17}[\alpha]_{\mathrm{D}}{ }^{20}-74.8$ (c $\left.\left.0.5, \mathrm{CHCl}_{3}\right)\right\} ; \mathrm{R}_{\mathrm{f}} 0.15$ (72:25:2:1, hexane/ $\mathrm{CH}_{2} \mathrm{Cl}_{2} / \mathrm{EtOH} / \mathrm{TEA}$ ); $96: 4$ er according to chiral HPLC analysis [ $\mathrm{t}_{\mathrm{R}}$ (minor) $14.98 \mathrm{~min}, \mathrm{t}_{\mathrm{R}}$ (major) $15.99 \mathrm{~min}$, see SI for details]; IR $v 2959,2911,2831,1614,1511$, 1426, 1244, 1153, 838, $770 \mathrm{~cm}^{-1} .{ }^{1} \mathrm{H}$ NMR (300 MHz, $\left.\mathrm{CDCl}_{3}\right) \delta 7.78$ (s, 1H), 7.77 (s, 1H), 7.20 (s, 1H), 7.08 (s, 1H), 4.33 (d, $J=15.2 \mathrm{~Hz}, 1 \mathrm{H}), 4.09$ (s, 6H), 4.04 (s, 3H), 4.03 (s, 3H), 3.56 (d, $J=15.2 \mathrm{~Hz}, 1 \mathrm{H}$ ), 3.29 (d, $J=10.7 \mathrm{~Hz}, 1 \mathrm{H}$ ), 3.05 (dd, $J=16.3,2.9$ Hz, 1H), 2.87 (dd, $J=16.3,10.7 \mathrm{~Hz}, 1 \mathrm{H}), 2.43-2.22$ (m, 2H), $2.08-1.95$ (m, 1H), $1.94-1.72(\mathrm{~m}, 3 \mathrm{H}), 1.63-1.34(\mathrm{~m}, 2 \mathrm{H}) \mathrm{ppm} ;{ }^{13} \mathrm{C}$ NMR (75 MHz, $\left.\mathrm{CDCl}_{3}\right) \delta 148.7$ (2C), $148.5(C), 148.4(C), 125.3(C), 125.2(C), 124.8(C), 123.9(C), 123.6(C), 123.4$ (C), $103.9(\mathrm{CH}), 103.5(\mathrm{CH}), 103.4(\mathrm{CH}), 103.1(\mathrm{CH}), 57.6(\mathrm{CH}), 56.4\left(\mathrm{CH}_{2}\right), 56.2$ $\left(\mathrm{CH}_{2}\right)$, $56.1(2 \mathrm{xCH}), 56.05\left(\mathrm{CH}_{3}\right), 56.02\left(\mathrm{CH}_{3}\right), 34.8\left(\mathrm{CH}_{2}\right), 33.7\left(\mathrm{CH}_{2}\right), 26.0\left(\mathrm{CH}_{2}\right)$, $24.4\left(\mathrm{CH}_{2}\right)$ ppm; HRMS (ESI-TOF) $\mathrm{m} / \mathrm{z}$ calcd for $\mathrm{C}_{25} \mathrm{H}_{30} \mathrm{NO}_{4} 408.2175[\mathrm{M}+\mathrm{H}]^{+}$, found 408.2185 . 
$\left(1 S, R_{S}\right)-N$-Allyl- $N$-(tert-butylsulfinyl)-1-allyl-2-[phenanthren-9-yl]-ethylamine (7a).

To a solution of sulfinamine $\mathbf{6}^{25}$ (319 $\mathrm{mg}, 0.87 \mathrm{mmol}$ ) in dry THF (3 mL) under argon atmosphere at $0{ }^{\circ} \mathrm{C}$ was added a solution of KHMDS in THF (0.8 M, $1.6 \mathrm{~mL}, 1.31$ mmol) via syringe. After stirring for $5 \mathrm{~min}$, allylbromide (150 $\mu \mathrm{L}, 1.74 \mathrm{mmol})$ was added to the solution and the reaction mixture was allowed to react for $1 \mathrm{~h}$ at $0{ }^{\circ} \mathrm{C}$. After this time, a solution of KHMDS in THF (0.8 M, $0.8 \mathrm{~mL}, 0.65 \mathrm{mmol})$ was added again and the reaction mixture was led to react for $1 \mathrm{~h}$ more at $0{ }^{\circ} \mathrm{C}$. After complete conversion of starting material (TLC in 8:2 hexane/EtOAc), the reaction was quenched by adding a saturated aqueous solution of $\mathrm{NH}_{4} \mathrm{Cl}(5 \mathrm{~mL})$ and the aqueous phase was extracted with EtOAc (3 x $10 \mathrm{~mL})$. The collected organic layers were washed with brine ( 2 x $5 \mathrm{~mL}$ ), dried over $\mathrm{MgSO}_{4}$ and concentrated under reduced pressure. The residue was purified by flash column chromatography (8:2 hexane/EtOAc), to give the expected product as a yellow wax (301 mg, 85\%): $[\alpha]_{\mathrm{D}}{ }^{20}+37.6\left(\right.$ c $\left.1.03, \mathrm{CHCl}_{3}\right) ; \mathrm{R}_{\mathrm{f}}$ 0.35 (8:2 hexane/EtOAc); IR v 2979, 1449, 1265, 1061, 994, 918, $727 \mathrm{~cm}^{-1} ;{ }^{1} \mathrm{H}$ NMR $\left(400 \mathrm{MHz}, \mathrm{CDCl}_{3}\right) \delta 8.86-8.69(\mathrm{~m}, 1 \mathrm{H}), 8.65(\mathrm{~d}, J=8.0 \mathrm{~Hz}, 1 \mathrm{H}), 8.18(\mathrm{~s}, 1 \mathrm{H}), 7.85$ (dd, $J=7.8,1.5 \mathrm{~Hz}, 1 \mathrm{H}$ ), 7.69 (s, 1H), $7.67-7.54$ (m, 4H), 5.85 (dddd, $J=9.4,7.7,6.2$, $3.9 \mathrm{~Hz}, 1 \mathrm{H}), 5.80-5.67$ (m, 1H), 5.16 (s, 1H), 5.13 (dd, $J=6.7,1.1 \mathrm{~Hz}, 1 \mathrm{H}), 5.02-$ 4.99 (m, 1H), 4.96 (dd, $J=13.2,1.7 \mathrm{~Hz}, 1 \mathrm{H}), 4.03$ (ddt, $J=16.5,4.6,1.7 \mathrm{~Hz}, 1 \mathrm{H}$ ), 3.75 (br s, $1 \mathrm{H}), 3.68$ (dd, $J=13.8,5.4 \mathrm{~Hz}, 1 \mathrm{H}), 3.41$ (dd, $J=13.8,8.7 \mathrm{~Hz}, 1 \mathrm{H}), 3.27$ (dd, $J=$ 16.5, $7.7 \mathrm{~Hz}, 1 \mathrm{H}$ ), 2.46 (ddd, $J=15.2,8.3,7.0 \mathrm{~Hz}, 1 \mathrm{H}), 2.36-2.26$ (m, 1H), 1.22 (s, 9H) ppm; ${ }^{13} \mathrm{C}$ NMR (101 MHz, $\left.\mathrm{CDCl}_{3}\right) \delta 136.1(\mathrm{CH}), 135.8(\mathrm{CH}), 133.4(\mathrm{C}), 131.8$ (C), $131.2(C), 130.9(C), 130.0(C), 128.7(C H), 128.4(\mathrm{CH}), 126.8(\mathrm{CH}), 126.7(\mathrm{CH})$, $126.4(2 x C H), 124.6(\mathrm{CH}), 123.5(\mathrm{CH}), 122.5(\mathrm{CH}), 117.9\left(\mathrm{CH}_{2}\right), 117.5\left(\mathrm{CH}_{2}\right), 61.7$ (CH), $58.3(\mathrm{C}), 46.4\left(\mathrm{CH}_{2}\right), 38.4\left(\mathrm{CH}_{2}\right), 37.9\left(\mathrm{CH}_{2}\right), 24.0\left(\mathrm{CH}_{3}\right) \mathrm{ppm}$; HRMS (EI) m/z calcd for $\mathrm{C}_{22} \mathrm{H}_{22} \mathrm{NOS}\left[\mathrm{M}^{+}-\mathrm{C}_{4} \mathrm{H}_{9}\right]$ 349.1417, found 349.1421. 
$\left(1 R, S_{\mathrm{S}}\right)-N$-Allyl- $N$-(tert-butylsulfinyl)-1-allyl-2-[phenanthren-9-yl]-ethylamine (ent-

7a). It was prepared in good yield (197 mg, 85\%) from ent-6 (210 mg, $0.57 \mathrm{mmol}$ ), using the same procedure described for the preparation of $\mathbf{7 a}$, and obtaining identical physical data, except for the optical rotation: $[\alpha]_{\mathrm{D}}{ }^{20}-37.5\left(c 1.03, \mathrm{CHCl}_{3}\right)$.

$\left(1 S, R_{S}\right)-N$-Allyl- $N$-(tert-butylsulfinyl)-1-allyl-2-(2,3,6,7-tetramethoxyphenanthren-

9-yl)-ethylamine (7b). Compound ent-1 ${ }^{21}$ (193 mg, $0.40 \mathrm{mmol}$ ) was submitted to the same procedure described to prepare compound 7a. The crude mixture was purified by flash column chromatography (6:4 hexane/EtOAc) to give the expected product as a white foam (153 mg, 73\%): $[\alpha]_{\mathrm{D}}{ }^{20}+51.6\left(c\right.$ 0.87, $\left.\mathrm{CHCl}_{3}\right)$; $\mathrm{R}_{\mathrm{f}} 0.19(1: 1$ hexane/EtOAc); IR $v 3079,2932,1618,1507,1473,1428,1251,1148,1040,839,773 \mathrm{~cm}^{-1} ;{ }^{1} \mathrm{H}$ NMR (400 MHz, $\mathrm{CDCl}_{3}$ ) $\delta 7.84$ (s, 1H), 7.77 (s, 1H), 7.55 (br s, 2H), 7.20 (s, 1H), 5.87 - 5.70 (m, 2H), $5.12-5.00$ (m, 4H), 4.13 (s, 3H), 4.11 (s, 3H), 4.09 (s, 3H), 4.03 (s, 3H), 3.99 (dd, $J=16.5,5.0 \mathrm{~Hz}, 1 \mathrm{H}$ ), 3.80 (br s, $1 \mathrm{H}$ ), 3.61 (dd, $J=13.9,6.0 \mathrm{~Hz}, 1 \mathrm{H}$ ), 3.34 (dd, $J=$ 13.6, 7.9 Hz, 1H), $3.30-3.16(\mathrm{~m}, 1 \mathrm{H}), 2.44$ (dt, $J=14.6,7.4 \mathrm{~Hz}, 1 \mathrm{H}), 2.40-2.29$ (m, 1H), 1.20 (s, 9H) ppm; ${ }^{13} \mathrm{C}$ NMR (101 MHz, $\left.\mathrm{CDCl}_{3}\right) \delta 149.2$ (C), $149.1(C), 149.0(C)$, $148.9(C), 136.0(\mathrm{CH}), 135.9(\mathrm{CH}), 130.9(C), 126.5(\mathrm{CH}), 126.4(C), 125.6(C), 125.1$ (C), $123.9(\mathrm{C}), 117.7\left(\mathrm{CH}_{2}\right), 117.6\left(\mathrm{CH}_{2}\right), 108.3(\mathrm{CH}), 105.5(\mathrm{CH}), 103.6(\mathrm{CH}), 103.0$ (CH), $60.8(\mathrm{CH}), 58.4(\mathrm{C}), 56.5\left(\mathrm{CH}_{3}\right), 56.3\left(\mathrm{CH}_{3}\right), 56.2\left(\mathrm{CH}_{3}\right), 56.1\left(\mathrm{CH}_{3}\right), 47.2$ $\left(\mathrm{CH}_{2}\right), 39.0\left(\mathrm{CH}_{2}\right), 38.4\left(\mathrm{CH}_{2}\right), 24.0\left(\mathrm{CH}_{3}\right)$ ppm; HRMS (EI) $\mathrm{m} / \mathrm{z}$ calcd for $\mathrm{C}_{26} \mathrm{H}_{30} \mathrm{NO}_{5} \mathrm{~S}\left[\mathrm{M}^{+}-\mathrm{C}_{4} \mathrm{H}_{9}\right]$ 468.1839, found 468.1849.

\section{$\left(2 S, R_{\mathrm{S}}\right)-N$-(tert-Butylsulfinyl)-2-(phenanthren-9-ylmethyl)-1,2,3,6-}

tetrahydropyridine (8a). Compound 7a (180 mg, $0.46 \mathrm{mmol})$ was placed into a $25 \mathrm{~mL}$ round-bottom-flask followed by second-generation Grubbs’ catalyst (20 mg, 0.023 mmol). The solids were put under argon atmosphere before dry $\mathrm{CH}_{2} \mathrm{Cl}_{2}(11 \mathrm{~mL})$ was added and the reaction mixture was stirred for $1 \mathrm{~h}$ at $25^{\circ} \mathrm{C}$, verifying completion of the 
reaction by TLC (8:2 hexane/EtOAc). The reaction mixture was concentrated and purified by flash column chromatography (8:2 hexane/EtOAc) to give the expected product as a white foam (159 mg, 95\%): mp $142.1-143.3{ }^{\circ} \mathrm{C}$; $[\alpha]_{\mathrm{D}}{ }^{20}+62.3($ c 1.03 , $\left.\mathrm{CHCl}_{3}\right) ; \mathrm{R}_{\mathrm{f}} 0.21$ (8:2 hexane/EtOAc); IR v 2999, 2948, 2835, 1446, 1244, 1064, 900, 750, $732 \mathrm{~cm}^{-1}$; ${ }^{1} \mathrm{H}$ NMR (400 MHz, $\mathrm{CDCl}_{3}$ ) $\delta 8.74$ (dd, $J=6.3,3.3 \mathrm{~Hz}, 1 \mathrm{H}$ ), 8.65 (d, $J$ $=8.2 \mathrm{~Hz}, 1 \mathrm{H}), 8.23(\mathrm{dd}, J=6.3,3.3 \mathrm{~Hz}, 1 \mathrm{H}), 7.82$ (dd, $J=7.7,1.5 \mathrm{~Hz}, 1 \mathrm{H}), 7.70-7.64$ (m, 2H), $7.64-7.57$ (m, 2H), $7.56(\mathrm{~s}, 1 \mathrm{H}), 5.92-5.76(\mathrm{~m}, 2 \mathrm{H}), 4.06-3.99(\mathrm{~m}, 1 \mathrm{H})$, 3.95 (d, $J=17.5 \mathrm{~Hz}, 1 \mathrm{H}$ ), 3.74 (dd, $J=18.0,3.7 \mathrm{~Hz}, 1 \mathrm{H}$ ), 3.53 (dd, $J=13.6,5.7 \mathrm{~Hz}$, 1H), 3.37 (dd, $J=13.6,9.3 \mathrm{~Hz}, 1 \mathrm{H}), 2.39$ (dd, $J=18.1,4.7 \mathrm{~Hz}, 1 \mathrm{H}), 1.99$ (d, $J=16.3$ Hz, 1H), 1.02 (s, 9H) ppm; ${ }^{13} \mathrm{C}$ NMR (101 MHz, $\left.\mathrm{CDCl}_{3}\right) \delta 133.9(C), 131.7(C), 131.3$ (C), $130.9(\mathrm{C}), 130.0(\mathrm{C}), 128.3(\mathrm{CH}), 128.2(\mathrm{CH}), 126.9(\mathrm{CH}), 126.8(\mathrm{CH}), 126.5$ (CH), $126.4(\mathrm{CH}), 125.3(\mathrm{CH}), 124.8(\mathrm{CH}), 123.8(\mathrm{CH}), 123.4(\mathrm{CH}), 122.6(\mathrm{CH}), 58.5$ (C), $55.6(\mathrm{CH}), 38.4\left(\mathrm{CH}_{2}\right), 36.3\left(\mathrm{CH}_{2}\right), 27.2\left(\mathrm{CH}_{2}\right), 23.2\left(\mathrm{CH}_{3}\right) \mathrm{ppm}$; HRMS (EI) m/z calcd for $\mathrm{C}_{20} \mathrm{H}_{18} \mathrm{NOS}\left[\mathrm{M}^{+}-\mathrm{C}_{4} \mathrm{H}_{9}\right] 320.1104$, found 320.1111 .

$\left(2 R, S_{\mathrm{S}}\right)-N-(t e r t-B u t y l s u l f i n y l)-2-(p h e n a n t h r e n-9-y l m e t h y l)-1,2,3,6-$

tetrahydropyridine (ent-8a). It was prepared in good yield (111 mg, 92\%) from ent7a (130 mg, $0.26 \mathrm{mmol}$ ), using the same procedure described for the preparation of 8a, and obtaining identical physical data, except for the optical rotation: $[\alpha]_{\mathrm{D}}{ }^{20}-60.9(\mathrm{c}$ 1.03, $\left.\mathrm{CHCl}_{3}\right)$.

$\left(2 S, R_{S}\right)-N$-(tert-Butylsulfinyl)-2-((2,3,6,7-tetramethoxyphenanthren-9-yl)methyl)1,2,3,6-tetrahydropyridine (8b). Compound 7b (153 mg, $0.29 \mathrm{mmol}$ ) was submitted to the same procedure described to prepare compound 8a. The crude mixture was purified by flash column chromatography (1:1 Hexane/EtOAc) to give the expected product as a white foam (135 mg, 93\%): $[\alpha]_{\mathrm{D}}{ }^{20}+87.8\left(c 0.87, \mathrm{CHCl}_{3}\right) ; \mathrm{R}_{\mathrm{f}} 0.22(1: 1$ hexane/EtOAc); 97:3 dr according to HPLC analysis [ $\mathrm{t}_{\mathrm{R}}$ (major) $11.55 \mathrm{~min}, \mathrm{t}_{\mathrm{R}}$ (minor) $13.52 \mathrm{~min}$, see SI 
for details]; IR $\vee 2949,2832,1618,1508,1473,1428,1251,1148,1042,750 \mathrm{~cm}^{-1} ;{ }^{1} \mathrm{H}$ NMR (400 MHz, $\mathrm{CDCl}_{3}$ ) $\delta 7.83$ (s, 1H), 7.77 (s, 1H), 7.75 (s, 1H), 7.35 (s, 1H), 7.16 (s, 1H), 5.86 (d, $J=2.8 \mathrm{~Hz}, 2 \mathrm{H}), 4.14$ (s, 3H), 4.13 (s, 3H), 4.11 (s, 3H), 4.08 (dd, $J=10.7$, $5.4 \mathrm{~Hz}, 1 \mathrm{H}), 4.04$ (s, 3H), 3.92 (d, $J=17.8 \mathrm{~Hz}, 1 \mathrm{H}), 3.81$ (d, $J=17.8 \mathrm{~Hz}, 1 \mathrm{H}), 3.47$ (dd, $J=13.2,4.7 \mathrm{~Hz}, 1 \mathrm{H}), 3.32$ (dd, $J=13.2,10.7 \mathrm{~Hz}, 1 \mathrm{H}), 2.28$ (dd, $J=18.0,5.2 \mathrm{~Hz}, 1 \mathrm{H})$, $1.98(\mathrm{~d}, J=17.0 \mathrm{~Hz}, 1 \mathrm{H}), 1.11(\mathrm{~s}, 9 \mathrm{H}) \mathrm{ppm} ;{ }^{13} \mathrm{C} \mathrm{NMR}\left(101 \mathrm{MHz}, \mathrm{CDCl}_{3}\right) \delta 149.1(\mathrm{C})$, $149.1(C), 149.0(C), 131.5$ (2xC), 126.3 (C), $125.9(C), 125.9(C H), 125.1(C), 125.0$ (CH), $124.2(\mathrm{CH}), 124.0(\mathrm{C}), 108.0(\mathrm{CH}), 105.8(\mathrm{CH}), 103.5(\mathrm{CH}), 103.0(\mathrm{CH}), 58.6$ (C), $56.5\left(\mathrm{CH}_{3}\right), 56.3\left(\mathrm{CH}_{3}\right), 56.2\left(\mathrm{CH}_{3}\right), 56.0\left(\mathrm{CH}_{3}\right), 53.0(\mathrm{CH}), 41.1\left(\mathrm{CH}_{2}\right), 35.8$ $\left(\mathrm{CH}_{2}\right), 27.0\left(\mathrm{CH}_{2}\right), 23.1\left(\mathrm{CH}_{3}\right)$ ppm; HRMS (EI) $\mathrm{m} / \mathrm{z}$ calcd for $\mathrm{C}_{24} \mathrm{H}_{26} \mathrm{NO}_{5} \mathrm{~S}\left[\mathrm{M}^{+}-\right.$ $\left.\mathrm{C}_{4} \mathrm{H}_{9}\right]$ 440.1526, found 440.1520.

$\left(2 S, R_{S}\right)-N$-(tert-Butylsulfinyl)-2-(phenanthren-9-ylmethyl)piperidine (9a). A $25 \mathrm{~mL}$ Schlenk tube was charged with compound 8a (149 mg, $0.40 \mathrm{mmol}$ ) and Adams’ catalyst (16 mg, $0.04 \mathrm{mmol}$ ). Air was evacuated and replaced by an argon atmosphere before adding dry $\mathrm{CH}_{2} \mathrm{Cl}_{2}(7.5 \mathrm{~mL})$ and EtOAc $(3 \mathrm{~mL})$. The schlenk tube was connected to a hydrogen balloon through a three-ways valve and the reaction mixture was put under hydrogen atmosphere after 3 cycles of freeze-pump and thaw. The resulting suspension was stirred at $25{ }^{\circ} \mathrm{C}$ for $24 \mathrm{~h}$, verifying completion of the reaction by TLC. The reaction mixture was concentrated and purified by column chromatography (8:2 hexane/EtOAc) to give the expected product as a white foam (139 mg, 93\%): mp $163.5-164.4{ }^{\circ} \mathrm{C}$; $[\alpha]_{\mathrm{D}}{ }^{20}+46.6\left(c \quad 0.90, \mathrm{CHCl}_{3}\right) ; \mathrm{R}_{\mathrm{f}} 0.25$ (8:2 hexane/EtOAc); IR $v 2972,2930,1452$, 1217, 1077, 1059, 910, 750, $734 \mathrm{~cm}^{-1} ;{ }^{1} \mathrm{H}$ NMR (400 MHz, $\left.\mathrm{CDCl}_{3}\right) \delta 8.73(\mathrm{~d}, J=9.6$ Hz, 1H), 8.65 (d, $J=8.9 \mathrm{~Hz}, 1 \mathrm{H}), 8.33$ (dd, $J=6.4,3.0 \mathrm{~Hz}, 1 \mathrm{H}), 7.85-7.79$ (m, 1H), $7.74-7.65$ (m, 2H), $7.65-7.53(\mathrm{~m}, 3 \mathrm{H}), 3.89$ (td, $J=8.4,3.8 \mathrm{~Hz}, 1 \mathrm{H}), 3.77$ (dd, $J=$ 13.3, 4.9 Hz, 1H), 3.50 - 3.37 (m, 1H), 3.31 (dd, $J=13.4,10.2 \mathrm{~Hz}, 1 \mathrm{H}), 3.27$ - 3.15 (m, 
1H), $1.96-1.76(\mathrm{~m}, 1 \mathrm{H}), 1.74-1.44(\mathrm{~m}, 6 \mathrm{H}), 1.13$ (s, 9H) ppm; ${ }^{13} \mathrm{C}$ NMR (101 MHz, $\left.\mathrm{CDCl}_{3}\right) \delta 133.7(C), 131.6(C), 131.2(C), 130.8(C), 129.9(C), 128.1(C H), 128.0$ (CH), $126.9(\mathrm{CH}), 126.6(\mathrm{CH}), 126.3(\mathrm{CH}), 126.2(\mathrm{CH}), 125.1(\mathrm{CH}), 123.2(\mathrm{CH}), 122.5$ (CH), $58.3(\mathrm{C}), 57.1(\mathrm{CH}), 42.5\left(\mathrm{CH}_{2}\right), 35.8\left(\mathrm{CH}_{2}\right), 28.4\left(\mathrm{CH}_{2}\right), 26.2\left(\mathrm{CH}_{2}\right), 23.3$ $\left(\mathrm{CH}_{3}\right), 19.9\left(\mathrm{CH}_{2}\right)$ ppm; HRMS (EI) $\mathrm{m} / \mathrm{z}$ calcd for $\mathrm{C}_{24} \mathrm{H}_{29} \mathrm{NOS}\left[\mathrm{M}^{+}-\mathrm{C}_{4} \mathrm{H}_{8}\right]$ 379.1970, found 379.1962.

$\left(2 R, S_{\mathrm{S}}\right)-N$-(tert-Butylsulfinyl)-2-(phenanthren-9-ylmethyl)piperidine (ent-9a). It was prepared in good yield (94 mg, 94\%) from ent-8a (101 mg, $0.26 \mathrm{mmol}$ ), using the same procedure described for the preparation of 9a, and obtaining identical physical data except for the optical rotation: $[\alpha]_{\mathrm{D}}^{20}-48.8\left(c 0.89, \mathrm{CHCl}_{3}\right)$.

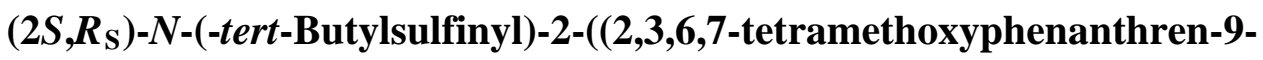

yl)methyl)piperidine (9b). Compound $8 \mathbf{b}$ (119 $\mathrm{mg}, 0.24 \mathrm{mmol}$ ) was submitted to the same procedure described to prepare compound 9a. The crude mixture was purified by column chromatography (1:1 Hexane/EtOAc) to give the expected product as a white foam $(100 \mathrm{mg}, 84 \%):[\alpha]_{\mathrm{D}}{ }^{20}+68.2\left(\right.$ ( $\left.0.67, \mathrm{CHCl}_{3}\right) ; \mathrm{R}_{\mathrm{f}} 0.36$ (1:1 hexane/EtOAc); $>99: 1 \mathrm{dr}$ according to HPLC analysis [ $\mathrm{t}_{\mathrm{R}}$ (major) $10.61 \mathrm{~min}$, see SI for details]; IR $v$ 3082, 2933, 2845, 1618, 1507, 1471, 1428, 1251, 1148, 1039, 912, $751 \mathrm{~cm}^{-1}$; ${ }^{1} \mathrm{H}$ NMR (400 MHz, $\left.\mathrm{CDCl}_{3}\right) \delta 7.88(\mathrm{~s}, 1 \mathrm{H}), 7.83(\mathrm{~s}, 1 \mathrm{H}), 7.77$ (s, 1H), 7.37 (s, 1H), $7.15(\mathrm{~s}, 1 \mathrm{H})$, 4.18 (s, 3H), 4.12 (s, 3H), 4.11 (s, 3H), 4.03 (s, 3H), 3.95 (dd, $J=10.9,4.2 \mathrm{~Hz}, 1 \mathrm{H})$, 3.65 (dd, $J=13.2,4.0 \mathrm{~Hz}, 1 \mathrm{H}), 3.57-3.48$ (m, 1H), 3.33 (dd, $J=13.2,11.3 \mathrm{~Hz}, 1 \mathrm{H}$ ), $3.16(\mathrm{dt}, J=13.0,3.9 \mathrm{~Hz}, 1 \mathrm{H}), 1.99-1.84(\mathrm{~m}, 1 \mathrm{H}), 1.77-1.58$ (m, 3H), $1.56-1.50$ (m, 2H), 1.16 (s, 9H) ppm; ${ }^{13} \mathrm{C}$ NMR (101 MHz, $\left.\mathrm{CDCl}_{3}\right) \delta 149.3(C), 149.2(C), 149.2$ (C), $149.1(C), 131.7(C), 126.4(C), 126.0(C), 125.8(C H), 125.8(C) 125.1(C), 124.1$ (C), $108.1(\mathrm{CH}), 106.3(\mathrm{CH}), 103.5(\mathrm{CH}), 103.1(\mathrm{CH}), 58.7(\mathrm{C}), 56.8\left(\mathrm{CH}_{3}\right), 56.4$ $\left(\mathrm{CH}_{3}\right), 56.3\left(\mathrm{CH}_{3}\right), 56.1\left(\mathrm{CH}_{3}\right), 54.6(\mathrm{CH}), 44.2\left(\mathrm{CH}_{2}\right), 35.6\left(\mathrm{CH}_{2}\right), 27.8\left(\mathrm{CH}_{2}\right), 26.4$ 
$\left(\mathrm{CH}_{2}\right), 23.4\left(\mathrm{CH}_{3}\right), 20.1\left(\mathrm{CH}_{2}\right)$ ppm; HRMS (EI) $\mathrm{m} / \mathrm{z}$ calcd for $\mathrm{C}_{24} \mathrm{H}_{28} \mathrm{NO}_{5} \mathrm{~S}\left[\mathrm{M}^{+}-\right.$ $\left.\mathrm{C}_{4} \mathrm{H}_{9}\right]$ 442.1683, found 442.1681.

(S)-11,12,13,14,14a,15-Hexahydro-9H-dibenzo[f,h]pyrido[1,2-b]isoquinoline $\quad((S)$ 10). To a pressure tube were sequentially added compound 9a (94 mg, $0.25 \mathrm{mmol}$ ), trifluoroacetic acid (2 mL, $62 \mathrm{mmol})$ and 37\% formalin $(0.95 \mathrm{~mL})$. The reaction mixture was put under argon atmosphere and heated to $90{ }^{\circ} \mathrm{C}$ while stirring for $12 \mathrm{~h}$ in the dark. After cooled to room temperature, the mixture was concentrated under vacuum and the residue was diluted with water $(5 \mathrm{~mL})$ and $4 \mathrm{M}$ solution of $\mathrm{NaOH}(2 \mathrm{~mL})$. The aqueous phase was extracted with EtOAc ( 3 x $10 \mathrm{~mL})$ and washed with brine $(5 \mathrm{~mL})$, dried over $\mathrm{Na}_{2} \mathrm{SO}_{4}$, and concentrated to dryness. Purification by flash column chromatography (72:25:2:1, hexane/ $\mathrm{CH}_{2} \mathrm{Cl}_{2} / \mathrm{EtOH} / \mathrm{TEA}$ ) afforded the desired product as a pale yellow solid (65 mg, 91\%): $[\alpha]_{\mathrm{D}}{ }^{20}+76 \quad$ (c $\left.\quad 0.4, \quad \mathrm{MeOH}\right) ; \quad \mathrm{R}_{\mathrm{f}} \quad 0.17 \quad(72: 25: 2: 1$, hexane/ $\mathrm{CH}_{2} \mathrm{Cl}_{2} / \mathrm{EtOH} / \mathrm{TEA}$ ); 96:4 er according to chiral HPLC analysis [ $\mathrm{t}_{\mathrm{R}}$ (major) 9.44 $\min , t_{R}$ (minor) 15.79 min, see SI for details]; IR v 3073, 2926, 2859, 2778, 2750, 1605, 1440, 1112, 752, $720 \mathrm{~cm}^{-1} ;{ }^{1} \mathrm{H}$ NMR (300 MHz, $\left.\mathrm{CDCl}_{3}\right) \delta 8.74-8.64$ (m, 2H), $8.05-$ 7.95 (m, 1H), $7.94-7.84$ (m, 1H), $7.67-7.55$ (m, 4H), 4.49 (d, $J=15.8 \mathrm{~Hz}, 1 \mathrm{H}), 3.68$ (d, $J=15.8 \mathrm{~Hz}, 1 \mathrm{H}), 3.35-3.17(\mathrm{~m}, 2 \mathrm{H}), 3.06-2.91(\mathrm{~m}, 1 \mathrm{H}), 2.48-2.26(\mathrm{~m}, 2 \mathrm{H})$, 2.12 - 1.99 (m, 1H), $1.95-1.70$ (m, 3H), 1.63 - 1.35 (m, 2H) ppm; ${ }^{13} \mathrm{C}$ NMR (75 MHz, $\left.\mathrm{CDCl}_{3}\right) \delta 131.1(C), 129.8(C), 129.6(C), 129.4(C), 127.8(C), 127.5(C), 126.8$ (2xCH), $125.9(\mathrm{CH}), 125.8(\mathrm{CH}), 123.4(\mathrm{CH}), 123.1(\mathrm{CH}), 122.9(\mathrm{CH}), 122.6(\mathrm{CH}), 57.6$ (CH), $56.4\left(\mathrm{CH}_{2}\right), 56.3\left(\mathrm{CH}_{2}\right), 34.9\left(\mathrm{CH}_{2}\right), 33.9\left(\mathrm{CH}_{2}\right), 26.1\left(\mathrm{CH}_{2}\right), 24.5\left(\mathrm{CH}_{2}\right) \mathrm{ppm}$; HRMS (EI) $m / z$ calcd for $\mathrm{C}_{21} \mathrm{H}_{21} \mathrm{~N} 287.1674$ found 287.1668.

(R)-11,12,13,14,14a,15-Hexahydro-9H-dibenzo[f,h]pyrido[1,2-b]isoquinoline $\quad((R)-$ 10). It was prepared in good yield (65 mg, 91\%) from ent-9b (80 mg, $0.16 \mathrm{mmol})$, following the same procedure described for the preparation of $\mathbf{1 0}$, and obtaining 
identical physical data, except for: $[\alpha]_{\mathrm{D}}^{20}-78$ ( $\left.0.5, \mathrm{MeOH}\right) ; 95: 5$ er according to chiral HPLC analysis [ $\mathrm{t}_{\mathrm{R}}$ (minor) $9.41 \mathrm{~min}, \mathrm{t}_{\mathrm{R}}$ (major) $15.75 \mathrm{~min}$, see SI for details].

(S)-7-Methoxycryptopleurine ((S)-5). To a pressure tube that contained a solution of compound $9 \mathbf{b}(80 \mathrm{mg}, 0.16 \mathrm{mmol})$ in $\mathrm{MeOH}(2 \mathrm{~mL})$ at $0^{\circ} \mathrm{C}$ was added a solution of $\mathrm{HCl}$ in dioxane (4M, $0.20 \mathrm{~mL})$. The mixture was put under argon atmosphere and stirred at room temperature during $5 \mathrm{~h}$. At this point the mixture was concentrated to dryness, and EtOH (4 mL), aqueous formaldehyde (37\%, $0.80 \mathrm{~mL})$ and concentrated $\mathrm{HCl}(12 \mathrm{M}$, $0.12 \mathrm{~mL}$ ), were sequentially added. The reaction mixture was put under argon atmosphere, protected from light irradiation and stirred at $90{ }^{\circ} \mathrm{C}$ during $48 \mathrm{~h}$. After cooled to room temperature, the mixture was concentrated and distributed between $2 \mathrm{M}$ solution of $\mathrm{NaOH}(10 \mathrm{~mL})$ and $\mathrm{CH}_{2} \mathrm{Cl}_{2}(15 \mathrm{~mL})$. The aqueous phase was extracted with $\mathrm{CH}_{2} \mathrm{Cl}_{2}$ (3 x $\left.10 \mathrm{~mL}\right)$ and the collected organic layers were washed with brine $(1 \times 5$ $\mathrm{mL}$ ), dried over $\mathrm{Na}_{2} \mathrm{SO}_{4}$, and concentrated in vacuum. Purification by flash chromatography (72:25:2:1, hexane/ $\mathrm{CH}_{2} \mathrm{Cl}_{2} / \mathrm{EtOH} / \mathrm{TEA}$ ) afforded the desired product as a yellow solid (53 mg, 81\%). Compound (S)-5 had identical physical data as reported for compound $(\boldsymbol{R})-5$, except for: $[\alpha]_{\mathrm{D}}{ }^{20}+84\left(\right.$ c 0.9, MeOH) $\left\{\right.$ lit. $^{17}[\alpha]_{\mathrm{D}}{ }^{20}+62.0$ (c 0.5, $\left.\mathrm{CHCl}_{3}\right)$ \}; >99:1 er according to chiral HPLC analysis [ $\mathrm{t}_{\mathrm{R}} 14.96 \mathrm{~min}$, see SI for details].

\section{ACKNOWLEDGMENTS}

We thank the Spanish Ministerio de Ciencia e Innovación (CTQ2011-24165) for financial support. I. B. acknowledges the Generalitat Valenciana for a postdoctoral fellowship (ACIF/2011/159). C. A.-T. thanks the ISO for a grant.

Supporting Information: Copies of ${ }^{1} \mathrm{H}$ and ${ }^{13} \mathrm{C}$ NMR spectra for compounds 2-10, and HPLC traces used for determination of diastereomeric or enantiomeric ratios. The doseresponse curves for compounds $(R)$-and $(S)$-5 against the four cancer cell lines 
examined, as well as general information related with the cytoxicity assays. This material is available free of charge via the Internet at http://pubs.acs.org.

(1) For a review, see: Chemler, S. R. Curr. Bioact. Comp. 2009, 5, 2.

(2) Wadhawan, V. K.; Sikka, S. K.; Mulchandani, N. B. Tetrahedron Lett. 1973, 14, 5091.

(3) (a) Chuang, T.-H.; Lee, S.-J.; Yang, C.-W.; Wu, P.-L. Org. Biomol. Chem. 2006, 4, 860. (b) We have observed the same preference for natural tetraponerines that exhibit fused quinolizidine and indolizidine frameworks, see: Bosque, I. Gonzalez-Gomez, J. C.; Guijarro, A.; Foubelo, F.; Yus, M. J. Org. Chem. 2012, 77, 10340.

(4) For a comprehensive review, see: Royer, J.; Bonin, M.; Micouin, L. Chem. Rev. 2004, 104, 2311.

(5) De la Lande, I. S. Aust. J. Exp. Biol. Med. Sci. 1948, 26, 181.

(6) Johns, S. R.; Lamberton, J. A.; Sioumis, A. A.; Willing, R. I. Aust. J. Chem. 1970, 23, 353.

(7) Luo, Y.; Liu, Y.; Luo, D.; Gao, X.; Li, B.; Zhang, G. Planta Medica 2003, 69, 842.

(8) Yan, J.; Luo, D.; Luo, Y.; Gao, X.; Zhang, G. Int. J. Gynecol. Cancer 2006, 16, 165.

(9) Wang, Z.; Wu, M.; Wang, Y.; Li, Z.; Wang, L.; Han, G.; Chen, F.; Liu, Y.; Wang, K.; Zhang, A.; Meng, L.; Wang, Q. Eur. J. Med. Chem. 2012, 51, 250.

(10) Dumoulin, D.; Lebrun, S.; Couture, A.; Deniau, E.; Grandclaudon, P. Eur. J. Org. Chem. 2010, 1943.

(11) Leighty, M. W.; Georg, G. I. ACS Med. Chem. Lett. 2011, 2, 313.

(12) For recent syntheses of racemic 7-methoxycryptopleurine, see: (a) Reference 3a.

(b) Orejarena Pacheco, J. C.; Lahm, G.; Opatz, T. J. Org. Chem. 2013, 78, 4985. 
(13) Yang, C. W.; Chuang, T. H.; Wu, P. L.; Huang, W. H.; Lee, S. J. Biochem. Biophys. Res. Commun. 2007, 354, 942.

(14) Lee, Y.-Z.; Yang, C.-W.; Hsu, H.-Y.; Qiu, Y.-Q.; Yeh, T.-K.; Chang, H.-Y.; Chao, Y.-S.; Lee, S.-J. J. Med. Chem. 2012, 55, 10363.

(15) Wang, Z.; Feng, A.; Cui, M.; Liu, Y.; Wang, Q. PLoS One 2012, 7, e52933.

(16) Wang, Z.; Feng, A.; Cui, M.; Liu, Y.; Wang, L.; Wang, Q. Chem. Biol. Drug Des. 2014, 84, 531.

(17) Wang, Z. W.; Wang, Q. M. Tetrahedron Lett. 2010, 51, 1377.

(18) For some examples that made use of a late Pictet-Spengler reaction, see: (a) Zeng, W.; Chemler, S. R. J. Org. Chem. 2008, 73, 6045. (b) Cui, M. B.; Song, H. J.; Feng, A. Z.; Wang, Z. W.; Wang, Q. M. J. Org. Chem. 2010, 75, 7018. (c) Mai, D. N.; Wolfe, J. P. J. Am. Chem. Soc. 2010, 132, 12157.

(19) Grubbs, R. H.; Miller, S. J.; Fu, G. C. Acc. Chem. Res. 1995, 28, 446.

(20) For a comprehensive review on the synthetic applications of chiral tertbutylsulfinamines, see: Robak, M. T.; Herbage, M. A.; Ellman, J. A. Chem. Rev. 2010, $110,3600$.

(21) Anton-Torrecillas, C.; Gonzalez-Gomez, J. C. Org. Biomol. Chem. 2014, 12, 7018. (22) While our work was ongoing, this general strategy was reported by the Wang`s group for the collective asymmetric synthesis of some phenanthroizidine alkaloids, see: Zheng, Y.; Liu, Y.; Wang, Q. J. Org. Chem. 2014, 79, 3348.

(23) For selected applications, see: (a) Ojima, I.; Tzamarioudaki, M.; Eguchi, M. J. Org. Chem. 1995, 60, 7078. (b) Petricci, E.; Mann, A.; Rota, A.; Schoenfelder, A.; Taddei, M. Org. Lett. 2006, 8, 3725. (c) Chiou, W.-H.; Schoenfelder, A.; Sun, L.; Mann, A.; Ojima, I. J. Org. Chem. 2007, 72, 9418. (d) Airiau, E.; Spangerberg, T.; Girard, N.; Schoenfelder, A.; Salvadori, J.; Taddei, M.; Mann, A. Chem.-Eur.J. 2008, 14, 10938. 
(e) Chiou, W.-H.; Lin, G.-H.; Hsu, C.-C.; Chaterpaul, S. J.; Ojima, I. Org. Lett. 2009, 11, 2659. (f) Airiau, E.; Girard, N.; Pizzeti, M.; Salvadori, J.; Taddei, M.; Mann, A. J. Org. Chem. 2010, 75, 8670.

(24) (a) Makado, G.; Morimoto, T.; Sugimoto, Y.; Tsutsumi, K.; Kagawa, N.; Kakiuchi, K. Adv. Synth. Catal. 2010, 352, 299. (b) Cini, E.; Airiau, E.; Girard, N.; Mann, A.; Salvadori, J.; Taddei, M. Synlett 2011, 199. (c) Ren, H.; Wulff, W. D. Org. Lett. 2013, $15,242$.

(25) We used this compound as a model because it is readily prepared in four steps, as we described in reference 21 , and illustrates the applicability of this methodology to other phenanthroquinolizidines.

(26) (a) Fürstner, A.; Langemann, K. J. Am. Chem. Soc. 1997, 119, 9130. (b) It is worth noting that the sulfinyl group is commonly being replaced before the RCM, see for example: reference 22.

(27) (a) Procupiou, G.; Lewis, W.; Harbottle, G.; Stockman, R. A. Org. Lett. 2013, 15, 2030. (b) Bosque, I.; Bagdatli, E.; Foubelo, F.; Gonzalez-Gomez, J. C. J. Org. Chem. 2014, 79, 1796. 